\title{
МЕЖДУНАРОДНОЕ ПРАВО РАЗВИТИЯ (ОСНОВНЫЕ ЧЕРТЫ И ТЕНДЕНЦИИ)
}

\author{
А.Ш. Н и 3 а м и е в $^{*}$
}

Идея международного права развития и само это название появились в 1964 году в работе А. Филиппа, в которой этот ученый говорил об образовании новой отрасли "международного коммерческого права для развития" , а позднее на симпозиуме в Ницце он впервые ввел термин "международное право развития" 2 . Эта идея в последуюшем была поддержана другим ученым - М. Виралли в его книге, посвященной международному праву развития ${ }^{3}$.

Следует отметить, что среди ученых, которые поднимают проблему развития, еще не сложилось единого мнения о месте международного права развития в системе международного права. В отличие от концепций международного экономического права, где единодушно признается самостоятельность этого права как отрасли международного права, в существуюших в настоящее время концепциях международного права развития нет единой позиции по вопросу о степени самостоятельности, автономности международного права развития.

Обращаясь к рассмотрению концепций международного права развития необходимо отметить, что одни ученые считают международное право развития частью международного экономического права, другие рассматривают в рамках международного экономического права только лишь проблемы развития, но не международное право развития, третьи признают международное право развития самостоятельной отраслью международного права, четвертые видят в этом праве одну из характеристик, или новое измерение современного международного права.

Среди ученых, которые рассматривают международное право развития как часть международного экономического права можно назвать профессора университета Майами Ф.В. Гарсиа-Амадора. Этот ученый отмечает, что пока международное право развития может рассматриваться как часть международного экономического права ${ }^{4}$. Однако, по его мнению, после того, как будет завершен процесс конкретизации и систематизации принципов и норм международного права развития, это право станет самостоятельным по отношению к международному экономическому праву5 ${ }^{5}$ До этого момента международное право развития будет оставаться лишь "новым измерением" международного экономического права.

Говоря о перспективе образования автономной отрасли, ученый приводит достаточно убедительные аргументы, которые уже в настоящее время позволяют говорить о специфике международного права развития. Прежде всего хотелось бы остановиться на такой особенности

*Аспирант и ассистент кафедры государственного и международного права Казанского Государственного Университета. 
международного права развития, как дуалистичный характер его норм (duality of norms), которую ученый выделил как наиболее яркий отличительный признак.

Международное право развития, пишет автор, является правовой системой, регулирующей отношения между различными категориями стран. В дополнение к отношениям между двумя главными группами (развитыми и развивающимися странами) стран оно также регулирует отношения развитых стран между собой по вопросам развития (например, на уровне ОЭСР) и между самими развивающимися странами. Дуалистичный характер норм международного права развития проявляется в отношениях между развитыми и развивающимися странами, и основывается на различном уровне развития стран, входящих в эти две большие группы, а также на различии в уровне развития стран, принадлежаших к группе развивающихся.

В связи с тем, что сторонниками международного права развития предлагается пересмотреть два принципа международного права взаимности и недискриминации - таким образом, чтобы предоставить определенные льготы менее развитым странам и тем самым способствовать сокращению неравенства в развитии, ученый видит дуализм норм международного права развития в преференциальном подходе к интересам развивающихся стран ${ }^{6}$.

Говоря о дуалистичности норм международного права развития, которая основана на преференциальном режиме развивающихся стран, ученый вполне логично подходит к выводу о том, что нормы этого права могут рассматриваться и как обладающие плюралистическим характером. Ученый предлагает говорить о плюралистичности норм международного права развития, поскольку в силу разной степени развития развивающихся государств, наименее развитые из них требуют, в свою очередь, более преференциального режима?

В качестве других особенностей международного права развития Ф. Гарсиа-Амадор отмечает функцию этого права - содействие развитию, характер источников этого права - в основном декларации и резолюции международных организаций, а также незавершенность процесса выработки принципов и норм этого права ${ }^{8}$.

Сам ученый определяет международное право развития как правовую систему, регулируюшую отношения между различными категориями государств. В дополнение к отношениям между двумя основными категориями государств (т.е. развитыми и развивающимися), международным правом развития также регулируются отношения развитых стран между собой и отношения между самими развиваюшимися странами. При этом качественная специфика норм международного права развития особенно ярко проявляется в отношениях между развитыми и развивающимися странами, так как является следствием различного уровня экономического развития ${ }^{9}$.

Недостатком концепции Ф. Гарсиа-Амадора, на мой взгляд, является то, что ученый не останавливается на вопросах системы этого права. Им лишь упоминается о таких сферах регулирования международного права развития, как регулирование и координация экономической деятельности государств (в которую включаются постоянный суверенитет 
над природными ресурсами, экспроприация и национализация, урегулирование инвестиционных споров и полномочия государств в сфере финансов и налогов), международная торговля, экономическая и техническая помощь ${ }^{10}$. Думается, исходя из перечня этих сфер, которые составцяют предмет регулирования, можно представить и структуру, внутреннее содержание и систему международного права развития.

Необходимо, однако, отметить, что сама идея выделения международного права развития, независимо от того, как обосновывалось его существование - в рамках международного экономического права или за его пределами, не получила всеобщего признания. Некоторые ученые до сих пор продолжают относить проблемы развития к сфере регулирования международного экономического права, не оперируя при этом категорией “международное право развития".

Например, Ж. Кастанеда пишет, что международное экономическое право должно принимать во внимание проблемы развития, и в особенности в таких сферах, как суверенитет над природными ресурсами, регулирование иностранных инвестиций, национализация, экспроприация, компенсации, передача технологии, погашение задолженности, финансовых отношений и др. ${ }^{11 .}$

Французский ученый Дюпюи П.-М. также относит проблемы экономического развития государств к области регулирования международного экономического права. Он пишет, что международное экономическое право, особенно в области развития, создает механизм для регуляции, коррекции и развития производства и обращения различных благ на основе большей справедливости и в большей эффективности. ${ }^{12}$

Обоснованию автономности международного права развития была посвящена работа Освальда де Риверо, где говорится, что международное право развития образует новую отрасль международного права, которая не отрицает правовое равенство государств, однако признает, что они различаются по экономическим параметрам и позициям в международной торговле. ${ }^{13}$

По мнению этого ученого, международное право развития должно заменить классические стандарты международного права, которые регулируют международный обмен, вследствие того, что современное международное право в большей мере направлено на решение специфических проблем развития, нежели на решение проблем войны и мира, как это было до Второй мировой войны ${ }^{14}$. Для этих целей, по мнению ученого, все страны должны быть разделены на развитые и развивающиеся. Такая классификация создает новые обязательства, новые принципы сотрудничества и необходимость в наличии специальных правовых норм.

В качестве источников международного права развития Освальд де Риверо указывает резолюции и рекомендации ООН, международные конвенции и соглашения. Эти новые правила должны постепенно заменить нормы классического международного права, которые регулируют мировую торговлю и составляют основу международного экономического порядка. ${ }^{15}$

Следует отметить, что подобные достаточно смелые высказывания о 
смене принципов классического международного права новыми принципами международного права, основанными на необходимости преодоления отставания в развитии, поддерживаются не всеми учеными. Так, например, французский ученый Проспер Вей, не отрицая автономности международного права развития, выступает против тех взглядов, где международное право развития, представляемое как молодое и гуманистичное, противопоставляется обшему международному праву, представляемому как право жесткое и эгоистичное. 16

Этот ученый заостряет внимание на тех особенностях международного права развития, которые приписываются этому праву в научной литературе. Так в частности, ученый останавливается на таких особых характеристиках международного права развития, как направленность на изменение существуюшей ситуации в целях уменьшения неравенства, в отличие от международного права, которое направлено на сохранение стабильности в межгосударственных отношениях. В качестве особенности международного права развития П. Вей отмечает присущий международному праву развития принцип "компенсационного неравенства" (inegalité compensatrice), посредством которого утверждается неравенство с целью восстановления равенства, тогда как международное право основано на принципе суверенного равенства государств. Отличительной характеристикой международного права развития, по мнению ученого, является также сопровождаюшая становление этого права напряженность, которая свидетельствует о непрерывной борьбе за преодоление существующих ограничений и обеспечение революционных изменений в праве. ${ }^{17}$

Ав̈тор подчеркивает необязательный характер источников международного права развития, которые составляет так называемое мягкое право (soft law), включающее хартии, программы, декларации и друтие документы, принятые в рамках нового международного экономического порядка. ${ }^{18}$

В работе другого сторонника автономности международного права развития Р. Бермежо отмечалось, что международное право развития не может полностью являться частью международного экономического права, поскольку предметом его регулирования являются не только экономические отношения, но также и отношения в области социального, политического, культурного и т.д. развития. ${ }^{19}$ Автор считает, что международное право развития определяется через его цель - преодоление экономической отсталости и зависимости.

Отличие концепции международного права развития, выдвинутой данным ученым, от многих других является то, что проблема развития переводится им не на уровень преодоления экономической отсталости государств, а на уровень развития личности и народов. Таким образом сама постановка проблемы получает гуманистический характер. Так, например, ученый отмечает, что "в конечном итоге международное право развития должно быть направлено не на развитие государств, а на развитие личности и народов"20.

Указанной цели вполне соответствует и то определение, которое дает международному праву развития этот ученый. Международное право развития определяется им как совокупность международных принци- 
пов, норм и институтов, направленных на преодоление отставания в развитии с целью обеспечения прав личности и народов. ${ }^{21}$ Однако, ученый признает, что поскольку это право еще находится в стадии становления, то его определение неизбежно будет содержать определенные недостатки.

Подобно другим сторонникам концепции международного права развития Р. Бермежо в работе не останавливается на вопросе о системе этого права. Однако автор, указывая в качестве цели этого международного права развития преодоление отсталости государств, в структуре работы выделил разделы, посвященные следующим вопросам: права и обязанности государств по установлению нового экономического порядка, передача технологий, а также реформирование международной валютной и финансовой систем.

Ученый Белградского университета М. Буладжик, рассматривая международное право развития как самостоятельную отрасль, определяет это право как право, регулируюшее отношения между суверенными, но экономически неравными государствами. По своей природе это транснациональный правовой комплекс, целью которого является установление нового экономического порядка. ${ }^{22}$

М. Буладжик рассматривает природу международного права развития с достаточно революционной позиции. Им подчеркивается всеобъемлющий, универсальный характер этого права. Этот ученый отмечает, что международное право развития не есть право третьего мира, а международное право современной эры развития человечества. Таким образом, М. Буладжик продолжает упомянутую выше линию, сторонники которой противопоставляют обшее международного право и международное право развития, как две антагонистичные системы.

Систему международного права развития можно вывести из того определения, которое было предложено М. Буладжиком, и согласно которому оно определялось как совокупность норм, регулирующих международные отношения в целях установления равенства, взаимопомощи, возмешения и компенсации за неэквивалентные отношения развивающихся стран с развитыми странами. ${ }^{23}$

Различие между международным экономическим правом и международным правом развития делает М. Беланже. Основой для такого различия М. Беланже видит в конечной цели этих правовых отраслей. Он пишет, что хотя международное экономическое право и международное право развития имеют один и тот же объект (юридические правила, применимые к международной экономической деятельности), однако перед ними стоят разные цели: в первом случае это применение международного права в отношениях между всеми государствами, при котором тем не менее в большей степени учитываются интересы индустриальных стран, во втором случае применение права таким образом, чтобы в основном учесть потребности развивающихся стран. ${ }^{24}$

По мнению М. Беланже, международное право развития отражает прежде всего идею трансформации международного экономического права под давлением развивающихся стран. Автором высказывается более смелая мысль о том, что международное экономическое право как 
минимум в первое время должно быть адаптировано к международному праву развития. 25

Говоря о соотношении международного экономического права и международного права развития, М. Беланже исходит прежде всего из истории становления международного права развития. Этот ученый выделяет две стадии в развитии международного права развития. Первая стадия (семидесятые-восьмидесятые годы) характеризуется определенной политизацией и конфликтностью. Вторая стадия (девяностые годы) - использованием этого права. В итоге М. Беланже отмечает, что в ходе эволюционного процесса международное право развития постепенно становится международным правом партнерства между развитыми и развивающимися странами. В перспективе, отмечает ученый международное экономическое право и международное право развития сольются в регулировании политических, социальных, культурных и гуманитарных факторов экономического развития. ${ }^{26}$

Ответвление в этой группе концепций образует концепция, предложенная В. Фридманом. В структуре международного права этот ученый выделяет международное право экономического развития. Появление в названии новой отрасли прилагательного "экономическое" указывает, в отличие от рассмотренных ранее концепций международного права развития, на ограничение сферы регулирования этого права вопросами экономического характера.

Под международным правом экономического развития В. Фридман понимает "совокупность принципов, определяюших правовые взаимоотношения развивающихся стран с иностранными инвесторами и с национальными и международными государственными учреждениями по оказанию помощи в целях развития. Эта сфера включает принципы контроля над естественными ресурсами, статус иностранных инвесторов, правовой характер соглашений о концессиях и принципы компенсации, совокупность правовых принципов, которые четко отличаются от правовых аспектов иностранных капиталовложений и других торговых сделок в развитых странах"..27

Обрашаясь к праву международного экономического развития, В. Фридман рассматривает такие явления, как соглашения об экономическом развитии, международные финансовые институты, совместные международные предприятия, национализация, экспроприация и другие формы государственного вмешательства в иностранные экономические интересы, а также вопросы статуса иностранных лиц. ${ }^{28}$

К сторонникам третьей группы концепций международного права развития, в которой это право рассматривается как новое измерение международного права, можно отнести Бенуну М. Этот ученый рассматривает международное право развития лишь как один из подходов к международному праву, как его аспект. Он отмечает, что международное право развития не может рассматриваться как автономная дисциплина или отрасль международного права со своим объектом регулирования, методами и источниками. Оно не может быть отграничено от друтих отраслей международного права, несмотря на свою экономическую природу.

М. Бенуна отмечает, что международное право развития не совпадает 
с международным экономическим правом, которое направлено на регулирование международных экономических обменов. ${ }^{29}$ Предмет международного права развития, пишет ученый, шире предмета международного экономического права. Однако, по мнению М. Бенуны, международное право развития пронизывает не все общее международное право, но только те его области, которые наиболее "чувствительны" к диалогу Север-Юr. ${ }^{30}$

Анализ сложившихся подходов к международному праву развития, позволяет выделить несколько основных признаков этого права. Прежде всего хотелось бы отметить тот факт, что концепции международного права развития находятся еще в стадии становления и требуют дальнейшей разработки. Это подчеркивается в работах, где говорится о том, что поскольку международное право развития находится еще в стадии формирования, то невозможно дать его определение, которое не было бы лишено недостатков. ${ }^{31}$ Также отмечалось, что юридические аспекты проблем, с которыми сталкиваются развивающиеся страны, не получили еще той степени внимания, которую получили вопросы третьего мира в других отраслях науки и особенно в экономике. ${ }^{32}$

Большинство концепций международного права развития исходит из того, что это право выходит за рамки экономики, хотя и является по своему объекту в значительной степени "экономическим". 33 Экономическая составляющая в этом праве является наиболее существенной, поскольку, как отмечалось в литературе, международная деятельность в области развития всегда имеет экономический эффект. ${ }^{34}$

Большое значение в развитии концепции международного права развития играет прежде всего одна из глобальных проблем современности - проблема преодоления отсталости в экономическом развитии. Концепции международного права развития исходят из признания данной проблемы и необходимости ее решения, и потому в равной мере разрабатываются как учеными развитых, так и развивающихся стран.

Основной акцент во многих концепциях международного права развития в настоящее время перемещен с вопросов предмета, метода, системы этого права на его цель - преодоление отсталости и установление нового экономического порядка. И хотя цель правового регулирования не всегда признается достаточным критерием для выделения самостоятельной отрасли, особенностью формирования международного права развития стала эволюция этого права через постановку цели.

Следствием этого, а также того, что доктрины международного права развития являются сравнительно молодыми и в недостаточной степени разработанными, является отсутствие достаточно глубокого учения о системе международного права развития. Это отмечалось, например, Де Ваартом, который говоря о работах М. Флори ${ }^{35}$ и А. Пеле ${ }^{36}$, критиковал этих ученых за отсутствие границ и внутреннего содержания в предложенных ими концепциях международного права развития ${ }^{37}$. Не зря также отмечалось, что международное право развития более разработано с точки зрения его целей, нежели с точки зрения его содержания. ${ }^{38}$

Исходя из предложенных определений международного права развития, содержания курсов, можно очертить круг наиболее характерных вопросов, включаемых в предмет регулирования этого права. В этот круг 
можно включить следующие вопросы: регулирование государственного суверенитета над природными ресурсами, национализация, экспроприация, компенсации, регулирование иностранных инвестиций, передача технологий, регулирование задолженности.

Характерной особенностью международного права развития является также юридическая природа источников этого права. Большей частью эти источники состоят из актов рекомендательного характера: резолюции, рекомендации, декларации международных организаций, т.е. акты, относимые к категории так называемого мягкого права. Хотя за указанными документами и признается определенная политическая сила, в основном обязательность норм международного права развития выводится из принципа сотрудничества, закрепленного в Уставе ООН.

Эволюция международного права развития к настояшему моменту происходила в пределах относительно непродолжительного периода времени. Тем не менее даже этот временной промежуток выявил некоторые тенденции, которые постепенно становились все более устойчивыми и ясно различимыми.

Одной из таких тенденций, на мой взгляд, является формирование международного права развития как самостоятельной отрасли международного права. С этой точки зрения представляется более обоснованно говорить не о становлении международного права развития как универсальной системы права, способной заменить международное право, но как об отрасли, которая придаст международному праву новое содержание.

В этой связи хотелось бы отметить, что международное право развития сконцентрируется в основном на регулировании взаимоотношений развитых и развивающих стран в целях преодоления отсталости. В результате этот блок вопросов постепенно перейдет из сферы регулирования современного международного экономического права в сферу регулирования новой отрасли. Однако нельзя сказать, что объем международного права развития будет исключительно за счет сужения сферы международного экономического права. Поскольку, как говорилось выше, международное право развития включает в себя помимо экономических социальные, гуманитарные, культурные и другие аспекты, формирование этого права будет также происходить и за счет других элементов системы международного права.

Учитывая тот факт, что проблемы развития практически не сходят с повестки дня многих международных организаций, вполне обоснованно можно сказать об усилении воли государств к преодолению отсталости и реформированию сложившихся стандартов международного сотрудничества. Именно эта воля, на мой взгляд, будет способствовать повышению степени императивности источников международного права развития. При этом тенденция постепенного увеличения среди источников этого права количества обязательных международно-правовых актов приведет в конечном итоге к качественно новому состоянию международного права развития. ${ }^{39}$

Усиление императивности международного права развития повлечет, в свою очередь, и повышение роли этого права в регулировании международных отношений. Этот процесс с каждым днем все отчетливее 
проявляется уже в настоящее время. Тем не менее весь потенциал этого права по настояшему может раскрыться только тогда, когда государства в своих отношениях перейдут от установленной в международном праве обшей обязанности сотрудничать к более конкретным обязательствам, закрепляемым в международных договорах.

1 Philip A. La conférence de Genève, amorce d'un mouvement mondial irreversible // Développement \& Civilisations. - 1964. - No. 19. - P.P. $52-54$.

${ }^{2}$ Colloque de Nice sur l'Adaptation de l'ONU au monde d'aujourd hui. 27-29 mai 1965. — Paris: Pédone, 1965. - P. 135.

${ }^{3}$ Virally $M$. Vers un droit international du développement. - Paris, 1965 - P.P. 3 - 12.

${ }^{4}$ Garcia-Amador F.V. The emerging international law of development. A new dimension of international economic law. - New York: Oceana Publications, 1990. - P. 22.

5 Ibid. - P. 48 .

${ }^{6}$ Ibid. - P. 38.

${ }^{7}$ Ibid. - P. 41 .

${ }^{8}$ Ibid. - P. 44.

${ }^{9}$ Ibid. - P. 37.

${ }^{10}$ Ibid. - P. P. $35-36$.

1 Castañeda J. Intriduction au titre III "Le droit des relations économiques intemationales". In: Droit intemational. Bilan et perspectives. Tome 2/ Rédacteur général Mohammed Bedjaoui. Paris: Edition A. Pedone, 1991. - P. P. 634 - 638.

${ }^{12}$ D up uy P.-M. Droit Intemational Public. 3e édition. - Paris: Edition Dalloz, 1995. - P. 473.

${ }^{13}$ Rivero B. O. New Economic Order and International Development Law. - Guilford: Biddles Lid., 1980. - PP. 9-10.

${ }^{14}$ Rivero B. O. New Economic Order and Intemational Development Law. _ Guilford: Biddles Lid., 1980. - P.9.

${ }^{15}$ Ibid. - PP. 9-10.

16 Weil $P$. Le droit international en quête de son identité. Cours général de droit international public. RCADI. 1992. VI. T. 237. — The Hague/Boston/London: Martinus Nijhoff Publishers, 1996. -P. 95 .

${ }^{17}$ Ibid. - P. P. $93-94$.

18 Ibid. - P. 94.

${ }^{19}$ Bermejo $R$. Vers un Nouvel Ordre Economic Intemational. These présentée a la Faculté de droit et des sciences économiques et sociales de l'Université de Fribourg Suisse pour l'obtention du grade de docteur en droit. - Fribourg: Editions Universitaires, 1982. - P. 142.

${ }^{20}$ Ibid. - P. 143.

21 Ibid. - P. 144.

${ }^{22}$ Bulajic $M$. A changing world calls for international development law. In: Legal Issues in International Trade. - London: Craham \& Trotman / Martinus Nijhoff, 1990. - P.P. 4 - 5 .

${ }^{23}$ Bulajic $M$. A changing world calls for international development law. In: Legal Issues in International Trade. - London: Craham \& Trotman, 1990. - P.P. 4 - 5.

${ }^{24}$ Bélanger $M$. Institutions Economiques International. La mondialisation économique et ses limites. 6 e édition refondue. - Paris: Economica, 1997. - P. 4.

${ }^{25}$ Ibid. - P. 4.

${ }^{26}$ Ibid. - P. 5 .

${ }^{27}$ Friedman W. The Changing Structure of Intemational Law. - London, 1964. - P. 374.

${ }^{28}$ Fridman $W$. The Changing Structure of International Law. - New York: Columbia University Press, 1966. - P.P. $177-181$.

${ }^{29}$ Bennouna $M$. Droit intemational du développement. Tiers monde et interpellation du droit international. - Paris: Berger-Levrault, 1983. - P. 17. 
${ }^{30}$ Ibid. - P. 19.

31 См., например: Flory M. Droit International du développement. - Paris: Presses Universitaires de France, 1977. - P. 29. Pellet A. Le droit international du développement. Paris: Presses Universitaires de France, 1978. - P. 53.

${ }^{32}$ De Waurt PJ.I.M. The concept of international development law. In: Le droit au développement au plan international. Colloque, La Haye, 16-18 Octobre 1979. - Alphen aan den Rijn: Sijthoff \& Noordhoff, 1980.-P. 121.

${ }^{33}$ A bellan $H$. V. Codificación y desarrollo progresivo del Derecho internacional del desarrollo // Revista española de Derecho intemational, 1976, nos 2-3. - P. 375.

${ }^{34}$ Virally $M$. Le cadre juridique international du développement. Vers une Charte international du développement // Développement \& civilisations. - 1967. - No. 32. - P. 70.

${ }^{35}$ Flory $M$. Droit Intemational du développement. - Paris: Presses Universitaires de France, 1977.

${ }^{36}$ Pellet A. Le droit intemational du développement. -- Paris: Presses Universitaires de France, 1978.

${ }^{37}$ De Waurt P. J. I. M. The concept of intemational development law. In: The right to development at the intemational level. Workshop. The Hague, 16-18 October 1979. - Alphen aan den Rijn: Sijthoff \& Noordhoff, 1980.-P. 122.

${ }^{38}$ Garcia-Amador F.V. The emerging intemational law of development. A new dimension of intemational economic law. - New York: Oceana Publications, 1990. - P. 42.

${ }^{39}$ Gerold $H$. Commercial Treaties. In: Encyclopedia of Public International Law. V. 8. Amsterdam: Elsevier Science Publishers B.V., 1992. - P. 91.

г. Казань

Статья поступила в редакцию в январе 20002.

\title{
ПОНЯТИЕ И ПРИНЦИПЫ ОТВЕТСТВЕННОСТИ В МЕЖДУНАРОДНОМ MPABE
}

\author{
Л.П.Р а с с ка 3 о в*, И.В. У п оров
}

В настоящее время в международном праве определен достагочно широкий круг транснациональных преступлений, то есть деяний, в той или иной степени посягаюших на международный правопорядок. За совершением преступлений должны следовать ответственность, наказание. Однако в этих вопросах в международном праве еше много неопределенного и спорного.

Прежде всего необходимо отметить, что в рамках ООН отсутствует какой-либо постоянный надгосударственный аппарат, имеюший полномочия принуждать государства или иных субъектов международного права преодолевать определенные неблагоприятные последствия, связанные с совершением деяний, признанных мировым сообшеством как

* Доктор юридических наук, профессор.

** Кандидат юридических наук (Краснодарский юридический институт МВД России). 